\title{
Deficiency of Bax and Bak protects photoreceptors from light damage in vivo
}

\author{
P Hahn ${ }^{1,2}$, T Lindsten $^{3}$, A Lyubarsky ${ }^{1,2}$, G-S Ying ${ }^{2}$, \\ EN Pugh Jr. ${ }^{1,2}$, CB Thompson ${ }^{3}$ and JL Dunaief ${ }^{*, 1,2}$ \\ ${ }^{1}$ FM Kirby Center for Molecular Ophthalmology, University of Pennsylvania, \\ Philadelphia, PA, USA \\ 2 Scheie Eye Institute, University of Pennsylvania, Philadelphia, PA, USA \\ 3 Departments of Medicine, Pathology, and Laboratory Medicine, Abramson \\ Family Cancer Research Institute, University of Pennsylvania, Philadelphia, \\ PA, USA \\ * Corresponding author: JL Dunaief, 305 Stellar Chance Labs, 422 Curie Blvd, \\ Philadelphia, PA 19104, USA. Tel: 215898 5235; Fax: 215573 3918; \\ E-mail: jdunaief@mail.med.upenn.edu
}

Received 27.2.04; revised 17.5.04; accepted 20.5.04; published online 23.7.04 Edited by $S$ Orrenius

\begin{abstract}
Photoreceptors of $\mathrm{bax}^{-/-} \mathrm{bak}^{-/-}$but neither $\mathrm{bax}^{-/-}$mice nor $\mathrm{bak}^{-1-}$ mice are protected from developmental apoptosis, suggesting that $\mathrm{bax}^{-/-} \mathrm{bak}^{-1-}$ photoreceptors may also be protected from pathologic apoptosis. To test this possibility, we exposed $\mathrm{bax}^{-/} \mathrm{bak}^{-/-}$and $\mathrm{bax}^{-/-}$mice to bright light, which normally induces photoreceptor death. Photoreceptors in $b a x^{-/-} b a k^{-1-}$ mice were protected from death compared to bax $^{-1-}$ mice as indicated by a reduction in the number of TUNEL-positive photoreceptor nuclei $24 \mathrm{~h}$ following light damage and almost complete preservation of photoreceptors 7 days following light damage. These results provide the first in vivo evidence that combined deficiency of Bax and Bak can rescue cells from a pathologic stimulus more effectively than Bax deficiency and suggest that combined deficiency of Bax and Bak may also protect cells from other insults.

Cell Death and Differentiation (2004) 11, 1192-1197.

doi:10.1038/sj.cdd. 4401486

Published online 23 July 2004
\end{abstract}

Keywords: Bax; Bak; apoptosis; light damage; photoreceptors; protection

Abbreviations: TUNEL, terminal deoxynucleotidyl transferase dUTP nick end-labeling; CNS, central nervous system; UV, ultraviolet; cGMP, cyclic guanosine monophosphate; AMD, agerelated macular degeneration; RP, retinitis pigmentosa; $\mathrm{ONH}$, optic nerve head; GEE, generalized equation estimate; ERG, electroretinogram; S.E.M., standard error of the mean; ONL, outer nuclear layer; OS, photoreceptor outer segment; IS, photoreceptor inner segment

\section{Introduction}

Apoptotic cell death is an essential component of normal development, particularly in the central nervous system (CNS), but apoptosis has also been implicated in disease states including neurodegenerative diseases. The $b c l-2$ family has recently emerged as central in regulating apoptosis through the balance of its pro- and antiapoptotic members. ${ }^{1}$ Bax and Bak, the only known systemically expressed multidomain proapoptotic $b c /-2$ family members, play an important role in both developmental and pathological apoptosis. Because of impaired developmental apoptosis, mice deficient in Bax and Bak retain interdigital webs, imperforate vaginas, and supernumerary CNS neural progenitor cells as well as rod photoreceptors in the retina. ${ }^{2,3}$ Because of impaired pathological apoptosis, cultured mouse embryonic fibroblasts deficient in Bax and Bak are resistant to numerous apoptosis-inducing stimuli in vitro, including staurosporine exposure, growth factor withdrawal, and ultraviolet (UV) irradiation. ${ }^{4}$

Mice subjected to experimental retinal detachment undergo photoreceptor apoptosis, but Bax-deficient mice are completely rescued from this apoptosis. ${ }^{5}$ The cell death in this model is most likely hypoxia induced, as breathing high oxygen content air can partially protect photoreceptors. ${ }^{6,7}$ Similarly, hypoxia-induced activation of the apoptotic pathway in vitro is rescued by Bax deficiency, and Bak activation in this system is dependent upon the presence of Bax. ${ }^{8}$ In contrast to the cell death induced by hypoxia, Bak can be activated in the absence of Bax when cell death is induced by staurosporine exposure, growth factor withdrawal, and UV irradiation. ${ }^{4}$ Similarly, in the retina, Bax deficiency is insufficient to protect photoreceptors from death induced by a mutation in the cyclic guanosine monophosphate (cGMP) phosphodiesterase, ${ }^{9}$ which may induce photoreceptor death by causing intracellular calcium overload. ${ }^{10}$

To determine whether combined Bax/Bak deficiency would protect photoreceptors in vivo in response to oxidative stress compared to Bax deficiency, we used the light damage model, which results in photoreceptor degeneration. ${ }^{11}$ In wild-type mice, light damage induces photoreceptor apoptosis in a cfos-dependent manner ${ }^{12-14}$ detectable with terminal deoxynucleotidyl transferase dUTP nick end-labeling (TUNEL) and DNA-laddering analysis. ${ }^{15}$ While the precise mechanism of light damage is not yet known, the protective effects of various antioxidants $^{16,17}$ and the appearance and/or upregulation of markers of oxidative stress following light damage ${ }^{18,19}$ have implicated photo-oxidative damage.

Light damage results in photoreceptor degeneration and has been used as a model to study some features of retinal degenerations including age-related macular degeneration (AMD) and retinitis pigmentosa (RP), blinding diseases that currently have no successful treatments. Because of the laminar organization of the normal retina with its defined number of photoreceptors, retinal light damage is an ideal system to investigate potentially protective in vivo effects of Bax/Bak deficiency.

It has been hypothesized that apoptotic cell death in neurodegenerations represents a pathologic reactivation of developmental apoptotic pathways. Overexpression of the 
antiapoptotic gene $b c l-2$, shown to reduce developmental apoptosis of neurons including ganglion cells, ${ }^{20}$ protects ganglion cells from apoptosis following pathologic in vivo axotomy. ${ }^{21}$ We have recently shown that deficiency of Bax and Bak blocks normal developmental apoptosis of rod photoreceptors, ${ }^{3}$ and overexpression of $b c l-x_{L}$, an antiapoptotic $b c l-2$ family member, blocks developmental lead exposure induced photoreceptor cell death. ${ }^{22}$

Bcl-2 family members may similarly be involved in additional photoreceptor degenerations. Overexpression of the antiapoptotic gene $b c /-2$ protects photoreceptors from pathologic stimuli in vivo, including genetically induced retinal degenerations ${ }^{23}$ and photic injury. ${ }^{23,24}$ Protection from genetically induced retinal degeneration is augmented by coexpression of $b c l-2$ binding protein $\mathrm{BAG}-1 .{ }^{25} \mathrm{Bcl}-2-$ mediated rescue is incomplete and transient, however, possibly because of the toxic effects of $b c /-2$ overexpression on photoreceptors. ${ }^{23}$ Overexpression of antiapoptotic gene $b c l-x_{L}$ is not toxic to photoreceptors but does not rescue photoreceptors from photic injury or genetic mutations. ${ }^{24}$ Bcl-2 inhibits the proapoptotic activity of Bax and $\mathrm{Bak}^{26}$ suggesting that, similar to overexpression of $b c /-2$, deficiency of Bax and Bak may protect against light damage. Unlike bcl-2 overexpression, deficiency of Bax and Bak does not cause photoreceptor degeneration ${ }^{3}$ and may confer a more complete rescue than $b c /-2$ overexpression. The purpose of this study is to investigate whether deficiency of Bax and Bak protects photoreceptors from light-induced cell death in vivo.

\section{Results}

\section{Protection from DNA cleavage}

To determine if deficiency of Bax and Bak protected retinas from light damage-induced cell death, bax $^{-/-}$bak $^{-/-}(n=3)$ and $\mathrm{bax}^{-/-}(n=3)$ retinas subjected to bright light exposure were analyzed by TUNEL $24 \mathrm{~h}$ later. Both bax $^{-/-}$and bax $^{-1-}$ bak $^{-1-}$ retinas contained TUNEL-positive photoreceptors (Figure 1). To quantify the difference in cell death, the numbers of TUNEL-positive photoreceptors were counted in three different sagittal sections per retina through the optic nerve head $(\mathrm{ONH})$. Bax ${ }^{-1-} \mathrm{bak}^{-/-}$retinas contained significantly fewer TUNEL-positive photoreceptors than bax $^{-/-}$ retinas, with mean \pm standard error of the mean (S.E.M.) of $53.0 \pm 9.7$ versus $100.9 \pm 8.2, P<0.0007$ (Figure $1 c$ ).

\section{Preservation of photoreceptor nuclei and inner/ outer segments}

\section{Light-damaged $\mathrm{bax}^{-/-} \mathrm{bak}^{-/-}$versus light-damaged bax ${ }^{-1}$}

To determine whether the decrease in the number of TUNELpositive photoreceptors $24 \mathrm{~h}$ following light damage corresponded to a longer-term preservation of photoreceptors, morphologic analysis was performed 1 week following light damage. Photoreceptors from noninjured $\mathrm{bax}^{-1-} \mathrm{bak}^{-1-}$ and $b x^{-1-}$ mice have no significant differences. ${ }^{3}$ At 1 week following light damage, $\mathrm{bax}^{-/-} \mathrm{bak}^{-/-}$eyes demonstrated substantial morphologic preservation of photoreceptors com-
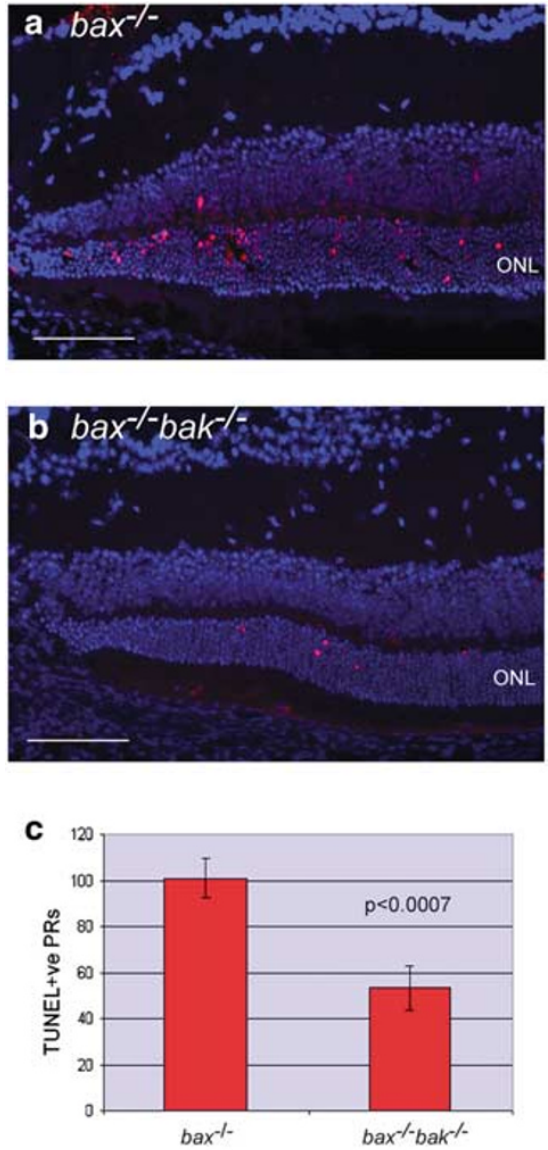

Figure 1 Fewer TUNEL-positive photoreceptor nuclei $24 \mathrm{~h}$ following light damage in $\mathrm{bax}^{-1-} \mathrm{bak}^{-1-}$ retinas compared to $\mathrm{bax}^{-1-}$ retinas. (a, b) Fluorescence photomicrographs of TUNEL-labeled retinas in the sagittal plane at the ONH demonstrate fewer TUNEL-positive nuclei (red) in $\mathrm{bax}^{-1-}$ bak $^{-/-}$(a) compared to $\mathrm{bax}^{-/}$(b) retinas $24 \mathrm{~h}$ following light damage. All nuclei are counterstained with DAPI (blue). Photoreceptor nuclei reside in the outer nuclear layer (ONL). Bar: $100 \mu \mathrm{m}$. (c) Histogram comparing numbers of TUNEL-positive photoreceptors from bax ${ }^{-1-} b^{-1-}(n=3)$ and $b^{-1-}(n=3)$ mice. The histogram displays the mean ( \pm S.E.M.) of total numbers of TUNEL-positive photoreceptors counted in three different sections per retina cut in the sagittal plane

pared to $b^{-1 /}$ eyes; bax ${ }^{-/-}$retinas compared to bax bak $^{-1-}$ retinas had profound thinning of the photoreceptor nuclear layer and disorganization and shortening of the photoreceptor inner/outer segments (Figures 2 and 3, Table 1 ). Both the $\mathrm{bax}^{-1-}$ and $\mathrm{bax}^{-/-} \mathrm{bak}^{-/-}$retinas were most severely affected centrally near the $\mathrm{ONH}$, with relative preservation of their peripheral retinas. The $\mathrm{bax}^{-/-} \mathrm{bak}^{-/-}$ photoreceptors appeared normal beyond approximately $750 \mu \mathrm{m}$ from the $\mathrm{ONH}$, while the damage to bax $^{-/}$retinas extended further to approximately $1500 \mu \mathrm{m}$ from the $\mathrm{ONH}$. The $b a x^{-/} b k^{-/-}$photoreceptors within $1500 \mu \mathrm{m}$ from the $\mathrm{ONH}$ were significantly protected compared to $\mathrm{bax}^{-/-}$photoreceptors; the $\mathrm{bax}^{-1-} \mathrm{bak}^{-1-}$ photoreceptor nuclear layer within $1500 \mu \mathrm{m}$ contained $2.86 \pm 0.84$ more nuclei per column compared with $\mathrm{bax}^{-/-}$retinas in the same region $(P<0.0001)$ and $11.5 \pm 3.68 \mu \mathrm{m}$ longer inner/outer segments $(P=0.002)$ (Table 1) 


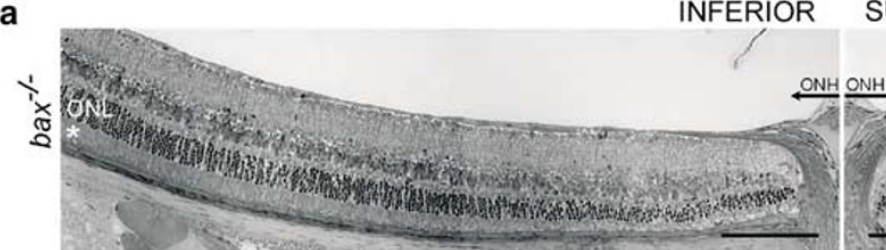

b

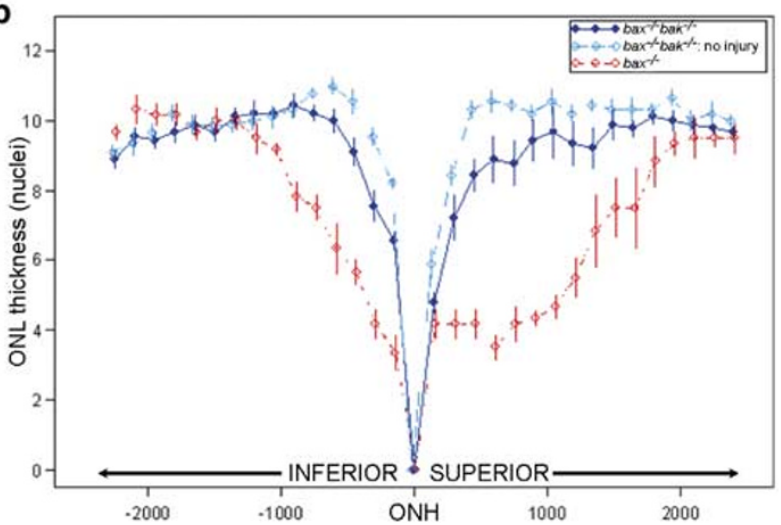

SUPERIOR
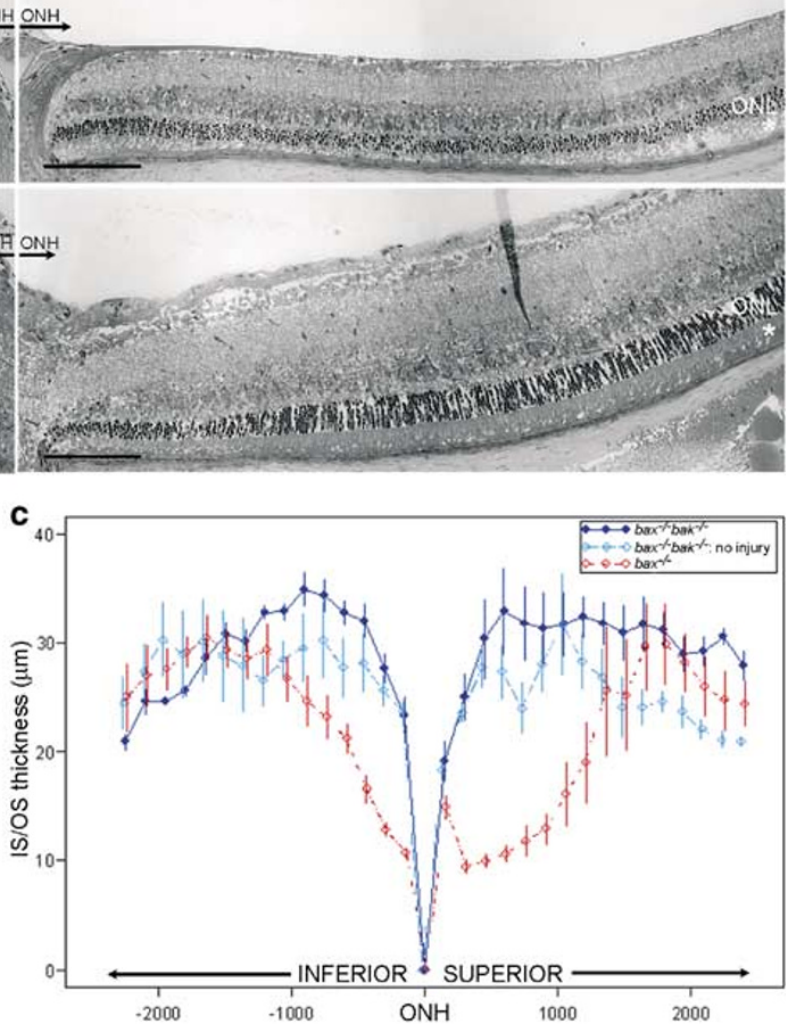

Figure 2 Near complete morphologic protection 7 days following light damage in bax ${ }^{-/-}$bak $^{-/-}$but not bax ${ }^{-/-}$retinas. (a) Photomicrographs of plastic sections from $\mathrm{bax}^{-/-}$bak $^{-/-}$and $b a x^{-/-}$retinas 7 days following light damage. Sagittal plane sections pass through the ONH. Both the inner and outer retinas of bax ${ }^{-/-}$bak ${ }^{-/-}$mice

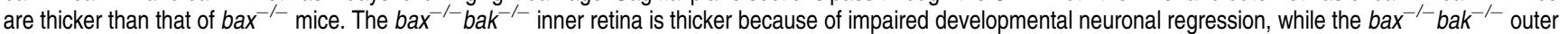
retina, namely photoreceptors in the outer nuclear layer (ONL) and inner/outer segments (IS/OS, labeled with *), are protected from light damage-induced thinning observed in the $\mathrm{bax}^{-/-}$outer retina. Bar: $150 \mu \mathrm{m}$. (b, c) Plot of the thickness of the ONL, measured in numbers of photoreceptor nuclei per column (b), or of the thickness of the inner/outer segments (IS/OS), measured in micrometers (c). Measurements were made in triplicate every $150 \mu \mathrm{m}^{2}$ away from the $\mathrm{ONH}$. Injured bax ${ }^{-1-}$ bak $^{-1-}$ $\left(n=3\right.$, dark blue) and $\mathrm{bax}^{-/-}\left(n=2\right.$, red) retinas 7 days following light damage and noninjured age-matched $\mathrm{bax}^{-/-}$bak $^{-/-}$retinas $(n=3$, light blue) are displayed as mean values $\left( \pm\right.$ S.E.M.). Noninjured age-matched $b a x^{-1-}$ retinas (not shown) are no different from noninjured $b^{-1-}$ bak $^{-/}$retinas

\section{Injured bax $^{-1-}$ bak $^{-1-}$ versus noninjured bax $^{-l-}$ bak $^{-1-}$}

To determine whether deficiency of Bax and Bak afforded complete protection against light damage, $\mathrm{bax}^{-1-} \mathrm{bak}^{-1-}$ retinas exposed to light damage were compared to nonexposed $b x^{-1-} b^{-1} k^{-1}$ retinas. While there was no statistically significant difference in inner/outer segment lengths, injured $\mathrm{bax}^{-/-} \mathrm{bak}^{-/-}$retinas had $0.9 \pm 0.47$ fewer photoreceptor nuclei $(P=0.04)$ within $1500 \mu \mathrm{m}$ from the ONH compared to noninjured $b x^{-/-} b^{-1 /-}$ retinas (Figure 2, Table 1).

\section{Retinal function assessed with electroretinography}

Compared to age-matched wild-type controls $(n=5)$, adult bax $^{-/-}(n=2)$ and bax $^{-/}$bak $^{-/-}(n=6)$ eyes had no significant loss of rod phototransduction as indicated by the saturating amplitude of the rod a-waves. Mean \pm S.E.M. scotopic a-wave amplitudes were $324 \pm 61 \mu \mathrm{V}$ for wild-type, $271 \pm 24 \mu \mathrm{V}$ for $\mathrm{bax}^{-/-}$, and $256 \pm 96 \mu \mathrm{V}$ for $\mathrm{bax}^{-1-} \mathrm{bak}^{-1-}$ retinas. Consistent with the nearly normal function of the rod photoreceptor cells, scotopic b-wave amplitudes, which are the field potential driven mainly by rod bipolars downstream of photoreceptors, were not significantly different in $\mathrm{bax}^{-/}$ $(272 \pm 68 \mu \mathrm{V})$ and $\mathrm{bax}^{-/-}$bak $^{-/-}(202 \pm 105 \mu \mathrm{V})$ retinas compared to wild-type retinas $(301 \pm 75 \mu \mathrm{V})$. While the number of animals used for the electroretinogram (ERG) analysis prohibits detailed statistical analysis, the electroretinographic data of the knockout mice show that retinal function of these mice is near to normal and establish that the absence of the bax and bak genes does not necessarily lead to loss of physiological function.

\section{Discussion}

Combined deficiency of proapoptotic $b c l-2$ family members, Bax and Bak, imparts resistance to developmental apopto$\mathrm{sis}^{2,3}$ and in vitro pathologic apoptosis. ${ }^{4}$ Bax deficiency alone is sufficient to protect completely photoreceptors from hypoxia-induced death caused by retinal detachment ${ }^{5}$ and to protect cells from hypoxia in vitro, ${ }^{8}$ but is not sufficient to protect cells in culture ${ }^{4}$ and photoreceptors in vivo from other types of apoptotic insult. ${ }^{3,9}$ We demonstrate here that combined deficiency of Bax and Bak in murine retinas 

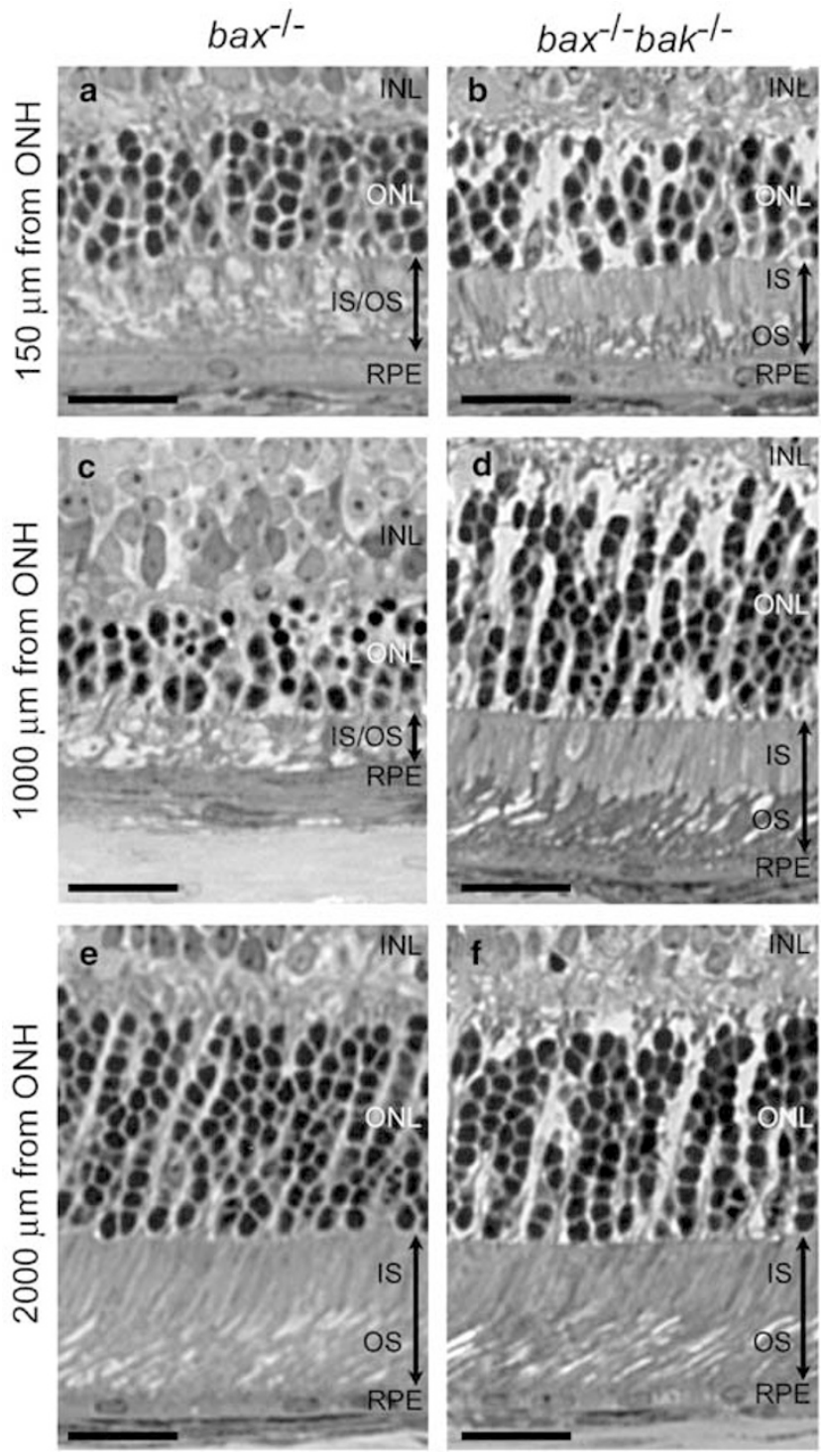

Figure 3 Protection against photoreceptor cell loss and inner/outer segmen shortening and disruption in $\mathrm{bax}^{-/-} \mathrm{bak}^{-/-}$compared to $\mathrm{bax}^{-/-}$retinas 7 days following light damage. (a-f) Photomicrographs of $1 \mu \mathrm{m}$ thick plastic sections at the indicated distances superior to the $\mathrm{ONH}$ from $\mathrm{bax}^{-1-}(\mathbf{a}, \mathbf{c}, \mathbf{e})$ and $\mathrm{bax}^{-1}$ bak ${ }^{-1-}(\mathbf{b}, \mathbf{d}, \mathbf{f})$ retinas 7 days following light damage. At $150 \mu \mathrm{m}$ from the $\mathrm{ONH}$ $(\mathbf{a}, \mathbf{b}), \mathrm{bax}^{-1-} \mathrm{bak}^{-1-}$ and $\mathrm{bax}^{-/-}$retinas have similar numbers of photoreceptor nuclei (ONL) and inner/outer segment (IS/OS) lengths (indicated by doubleheaded arrow), although the inner/outer segments in the $b^{-1-}$ retina are disorganized, unlike those in the $b^{-1-}$ bak $^{-/-}$retina. At $1000 \mu \mathrm{m}$ from the ONH (c, d), protection conferred by deficiency of Bax and Bak is demonstrated by the marked photoreceptor cell loss and IS/OS shortening and disruption not observed in the $\mathrm{bax}^{-/-} \mathrm{bak}^{-/-}$retina. Light damage is minimal in the periphery, and by $2000 \mu \mathrm{m}$ from the $\mathrm{ONH}(\mathbf{e}, \mathbf{f})$, bax $^{-1-}$ retinas have a normal number of ONL photoreceptors and a normal IS/OS length and organization, similar to bax ${ }^{-1}$ bak $^{-1-}$ retinas. Bar: $25 \mu \mathrm{m}$

significantly protects photoreceptors from degeneration induced by acute light damage relative to Bax deficiency; $\mathrm{bax}^{-/-} \mathrm{bak}^{-1-}$ retinas exposed to light damage had decreased photoreceptor cell death with resulting preservation of photoreceptor morphology compared with $\mathrm{bax}^{-/-}$retinas.

The photoreceptor protection observed with deficiency of Bax and Bak is consistent with previous studies, which have demonstrated protection from light damage by overexpression of the antiapoptotic gene $\mathrm{bcl}-2 .^{23} \mathrm{Bcl}-2$ overexpression, however, was toxic to photoreceptors, and resulting protection was incomplete with 3-4 rows of nuclei remaining after 14 days of constant light exposure. In contrast, deficiency of Bax and Bak does not cause photoreceptor death. ${ }^{3}$ Instead, it results in nearly complete protection 7 days following acute light damage; $\mathrm{bax}^{-/-} \mathrm{bak}^{-/-}$photoreceptors exposed to light damage retained approximately 9-10 rows of nuclei, and morphometric analysis was required to detect a small difference of only $0.90 \pm 0.47$ fewer nuclei in injured compared to noninjured $\mathrm{bax}^{-/-} \mathrm{bak}^{-1-}$ retinas.

Protection of photoreceptor morphology and number of nuclei in $\mathrm{bax}^{-/-} \mathrm{bak}^{-/-}$retinas was more significant than reduction of TUNEL-positive photoreceptors. This result can be explained by the observation that following light damage more photoreceptors become TUNEL positive than ultimately die. ${ }^{27}$ Thus, many of the TUNEL-positive photoreceptors in $b a x^{-1-} b k^{-/-}$retinas may have nonlethal DNA nicks, perhaps resulting from photo-oxidative stress.

While the precise mechanism of light damage is unclear, functional rhodopsin mediates its pathological consequences. ${ }^{28}$ We performed ERGs on 2-month-old bax $^{-1}$ ${ }^{-} \mathrm{bak}^{-1-}, \mathrm{bax}^{-/-}$, and wild-type animals to determine whether the protection observed in the $\mathrm{bax}^{-/-} \mathrm{bak}^{-/-}$retinas was due to decreased phototransduction. There were no significant differences in the rod a-waves among animals, suggesting that differences in photoreceptor phototransduction do not account for the photoreceptor protection in $\mathrm{bax}^{-1-} \mathrm{bak}^{-/-}$ mice. Another ERG study on 6-month-old $b^{-1-}$ and wildtype mice similarly demonstrated normal photoreceptor responses. ${ }^{29}$ This study also detected decreased b-wave amplitudes in $\mathrm{bax}^{-/-}$mice, indicative of decreased numbers of responsive INL bipolar cells. The b-wave amplitudes in our $\mathrm{bax}^{-1-}$ and $\mathrm{bax}^{-/-} \mathrm{bak}^{-/-}$mice were similar to wild type. This discrepancy is most likely a result of age-related changes that reduce bipolar responsiveness in the older, 6-month-old mice but not the 2-month-old mice in our study. This study and our current study are consistent in the finding of normal a-waves, suggesting that changes in bipolar responsiveness are independent of any changes in rod photoreceptor phototransduction.

With normal photoreceptor phototransduction, the decreased photoreceptor cell death in $\mathrm{bax}^{-/-} \mathrm{bak}^{-/-}$retinas most likely resulted from loss of the proapoptotic functions of Bax and Bak. Deficiency of both Bax and Bak in cultured MEFs, but not either one individually, imparts resistance to apoptotic stimuli in vitro, ${ }^{4}$ and increases in Bax and Bak proteins have been observed in $\mathrm{PC} 12$ cells exposed to $\mathrm{H}_{2} \mathrm{O}_{2}$ induced oxidative stress. ${ }^{30}$ Resistance of $\mathrm{bax}^{-/-} \mathrm{bak}^{-/-}$ photoreceptors to photo-oxidative injury is consistent with these in vitro results.

The bax gene is closely linked to pigment-related loci pinkeyed dilution $(p)$ and tyrosinase (Tyr), and mice homozygous for bax deletion ( $\mathrm{bax}^{-/-}$and $\mathrm{bax}^{-/-} \mathrm{bak}^{-/-}$mice) are lightly pigmented despite their C57BL/6 background (Jax Bulletin Number 2 (1999), from http://jaxmice.jax.org/info/bulletin/ bulletin02.html). Consequently, we were unable to compare light damage in the lightly pigmented $\mathrm{bax}^{-/} \mathrm{bak}^{-/}$and $\mathrm{bax}^{-1-}$ mice to heavily pigmented wild-type C57BL/6 mice 
Table 1 Comparison of numbers of photoreceptor nuclei per column and photoreceptor inner/outer segment length $(\mu \mathrm{m})$

\begin{tabular}{|c|c|c|c|c|c|c|}
\hline & \multicolumn{3}{|c|}{ Injured bax $^{-/}$bak $^{-/-}$versus bak ba- $^{-/}$} & \multicolumn{3}{|c|}{ bax $^{-/}$bak $^{-/-}$(injured versus noninjured) } \\
\hline & & PR nuclei & IS/OS length & & PR nuclei & IS/OS length \\
\hline $\begin{array}{l}\text { Mean (S.E.M.) } \\
\text { Difference }(95 \% \mathrm{Cl}) \\
P \text {-value }\end{array}$ & $\begin{array}{l}\text { bax }^{-1-} \text { bak }^{-1-} \\
\text { bax }^{-1-}\end{array}$ & $\begin{array}{l}8.99(0.43) \\
6.13(0.41) \\
2.86(1.70,4.02) \\
<0.0001\end{array}$ & $\begin{array}{l}30.5(2.24) \\
19.0(2.92) \\
11.5(4.32,18.7) \\
0.002\end{array}$ & $\begin{array}{l}\text { With injury } \\
\text { Without injury }\end{array}$ & $\begin{array}{l}8.99(0.43) \\
9.89(0.04) \\
0.90(0.06,1.75) \\
0.04\end{array}$ & $\begin{array}{l}30.5(2.24) \\
26.7(3.78) \\
3.61(-5.00,12.2) \\
0.41\end{array}$ \\
\hline
\end{tabular}

and $b_{a k}{ }^{-1-}$ mice. Melanin pigment in the iris, retinal pigment epithelium, and choroid absorbs light and protects the retina from light damage, and these wild-type mice are thus highly resistant to light-induced photoreceptor cell death. Because we compared light damage in $\mathrm{bax}^{-/-} \mathrm{bak}^{-/-}$and $\mathrm{bax}^{-/-}$, but not wild-type or $b_{a k^{-/}}$retinas, we were unable to make any conclusions about the individual roles of Bax and Bak in mediating light damage-induced photoreceptor apoptosis; we can only conclude that Bax deficiency is insufficient to protect completely photoreceptors from light damage and that combined Bax/Bak deficiency affords greater protection. Bax and Bak serve overlapping functions in developmental photoreceptor apoptosis such that loss of both is required for maximal impairment of developmental cell death, and it is likely that they serve similar roles in light damage-induced apoptosis.

The $\mathrm{bax}^{-1-} \mathrm{bak}^{-1-}$ mice have poor viability because of severe developmental abnormalities, and less than $10 \%$ of pups survive beyond the neonatal period. Thus, only a small number of adult mice were available for study. We are currently generating conditional, retina-specific knockout mice. Their improved viability will allow us to dissect the individual roles of Bax and Bak in light damage and determine the extent of protection afforded by Bax/Bak deficiency compared to wild type.

We have shown previously that Bax and Bak are important mediators of developmental photoreceptor apoptosis, ${ }^{3}$ and this current study provides evidence that Bax and Bak are similarly important in mediating light damage-induced cell death. Apoptosis represents the final common pathway of many retinal and other neurodegenerations, and targeting both Bax and Bak is therapeutically attractive. The protection of Bax/Bak-deficient mice from light damage demonstrates a role for these proapoptotic factors in an in vivo form of pathological death and warrants investigation into the involvement of Bax and Bak in other neurodegenerative processes.

\section{Materials and Methods}

\section{Mouse light damage}

The $b^{-1-}$ and $b^{-1-}$ bak $^{-/-}$mice were generated in a C57BL/6 background as previously described. ${ }^{2}$ Mice were reared with a light-dark cycle of $12 \mathrm{~h}$. Adult (2-3 months) mice were dark adapted for $12 \mathrm{~h}$, pupils were dilated with topical atropine $1 \%$, and mice were exposed to $10 \mathrm{k} \mathrm{lux}$ of cool white fluorescent light in a well-ventilated room for $7 \mathrm{~h}$ from 0200 to 0900 as described. ${ }^{19}$ Eyes were enucleated immediately following killing after either $24 \mathrm{~h}$ following light damage for TUNEL analysis or 7 days following light damage for morphologic analysis. All procedures concerning animals were approved by the University of Pennsylvania Institutional Animal Care and Use Committee and adhered to the ARVO Statement for the Use of Animals in Ophthalmic and Vision Research.

\section{TUNEL analysis}

Eyes enucleated $24 \mathrm{~h}$ following light damage were immersion fixed in $4 \%$ paraformaldehyde for $2 \mathrm{~h}$. Eyecups generated by removal of the anterior segment were cryoprotected overnight in 30\% sucrose and then embedded in Tissue-Tek OCT (Sakura Finetek, Torrance, CA, USA). Cryosections $10 \mu \mathrm{m}$ thick were cut in the sagittal plane through the $\mathrm{ONH}$. The fluorescein-conjugated TUNEL in situ cell death detection kit (Roche, Mannheim, Germany) was applied to sections according to the manufacturer's protocol. TUNEL-labeled sections were analyzed by fluorescent microscopy using a Nikon Eclipse TE-300 microscope (Nikon Inc., Melville, NY, USA), and digitized images were acquired with a Spot RT Slider camera (Diagnostic Instrument Inc., Sterling Heights, MI, USA) with ImagePro Plus v.4.1 software (Media Cybernetics, Silver Spring, MD, USA). For each retina, the number of TUNEL-positive photoreceptors was counted in three sagittal sections through the $\mathrm{ONH}$. The mean number of TUNEL-positive photoreceptors per bax $^{-/-}$bak $^{-/}$retina $(n=3)$ was compared to that from bax $^{-1-}$ retinas $(n=3)$ by the Student's $t$-test.

\section{Morphologic analysis}

Eyes enucleated 7 days following light damage were immersion fixed in $2 \%$ paraformaldehyde/2\% glutaraldehyde overnight. Eyecups generated by removal of the anterior segment were embedded in JB-4 plastic according to the manufacturer's protocol (Polysciences Inc., Warrington, $\mathrm{PA}, \mathrm{USA})$. Semi-thin sections $1 \mu \mathrm{m}$ thick were cut in the sagittal plane through the $\mathrm{ONH}$ and stained with 30\% Richardson's methylene blue/ azure II.

Digitized images of each section were acquired with a light microscope as described above. The number of nuclei per column of outer nuclear layer (ONL) photoreceptors was counted in triplicate at $150 \mu \mathrm{m}$ intervals from the $\mathrm{ONH}$ to $2100 \mu \mathrm{m}$ from the $\mathrm{ONH}$. The thickness of the inner/outer segments was also measured in triplicate at the same intervals, using image analysis software (ImagePro Plus, ver 4.1; Media Cybernetics) to calculate distances from manually set lengths.

Statistical comparisons were performed by calculating the means of each measurement (photoreceptor nuclei count and inner/outer segment thickness) for injured bax $^{-/-}$bak $^{-/-}(n=3)$ and bax $^{-1-}(n=2)$ retinas and for noninjured $b_{a x}{ }^{-/}$bak ${ }^{-/-}$retinas $(n=3)$ at each distance from the $\mathrm{ONH}$. Injured $\mathrm{bax}^{-/-} \mathrm{bak}^{-/-}$mice were compared to either injured bax ${ }^{-/-}$ mice or noninjured $b_{a x}{ }^{-1-} b_{a k}{ }^{-1-}$ mice. The S.E.M. and the differences in each measurement, along with their 95\% confidence intervals and $P$ values, were calculated from the generalized equation estimate (GEE) with adjustments for inter-eye correlations and correlations among repeated measurements from the same eye. ${ }^{31}$ Because light damage 
injured the region within $1500 \mu \mathrm{m}$ on each side of the $\mathrm{ONH}$, statistical analyses were performed on data gathered from this region. All data analyses were performed in SAS 8.2 (SAS Institute Inc., Cary, NC, USA).

\section{Electroretinography}

Retinal function of adult (2-3 months) $\mathrm{bax}^{-/-} \mathrm{bak}^{-1-}(n=6), \mathrm{bax}^{-/-}$ $(n=2)$, and wild-type $(n=5)$ mice was assessed by full field ERGs as previously described. ${ }^{32}$ Briefly, mice were anesthetized with xylazine/ ketamine and their eyes dilated with 1\% tropicamide (Alconox, New York, NY, USA). These mice were placed on a holding unit preheated to $38^{\circ} \mathrm{C}$. A platinum wire electrode was placed on the cornea using $2.5 \%$ hydroxypropyl methylcellulose (Goniosol; Ciba Vision, Duluth, GA, USA) as a protector, and a reference tungsten wire electrode was placed into the mouth. These mice were placed inside a Faraday cage and exposed to a series of stimuli to test the field potential of rods and rod-driven retinal bipolar function.

\section{Acknowledgements}

We thank Tzvete Dentchev for advice and assistance. This work was supported by a Research to Prevent Blindness Career Development Award, Steinbach Foundation, International Retina Research Foundation, $\mathrm{NIH/NEI} \mathrm{EY00417,} \mathrm{and} \mathrm{the} \mathrm{FM} \mathrm{Kirby} \mathrm{Foundation.}$

\section{References}

1. Adams JM and Cory S (1998) The Bcl-2 protein family: arbiters of cell survival. Science 281: 1322-1326

2. Lindsten $T$, Ross AJ, King A, Zong WX, Rathmell JC, Shiels HA, Ulrich E, Waymire KG, Mahar P, Frauwirth K, Chen Y, Wei M, Eng VM, Adelman DM, Simon MC, Ma A, Golden JA, Evan G, Korsmeyer SJ, MacGregor GR and Thompson CB (2000) The combined functions of proapoptotic Bcl-2 family members bak and bax are essential for normal development of multiple tissues. Mol. Cell 6: 1389-1399

3. Hahn P, Lindsten T, Ying GS, Bennett J, Milam AH, Thompson CB and Dunaief JL (2003) Proapoptotic bcl-2 family members, Bax and Bak, are essential for developmental photoreceptor apoptosis. Invest. Ophthalmol. Vis. Sci. 44: 3598-3605

4. Wei MC, Zong WX, Cheng EH, Lindsten T, Panoutsakopoulou V, Ross AJ, Roth KA, MacGregor GR, Thompson CB and Korsmeyer SJ (2001) Proapoptotic $B A X$ and BAK: a requisite gateway to mitochondrial dysfunction and death. Science 292: 727-730

5. Yang L, Bula D, Arroyo JG and Chen DF (2004) Preventing retinal detachmentassociated photoreceptor cell loss in Bax-deficient mice. Invest. Ophthalmol. Vis. Sci. 45: 648-654

6. Mervin K, Valter K, Maslim J, Lewis G, Fisher S and Stone J (1999) Limiting photoreceptor death and deconstruction during experimental retinal detachment: the value of oxygen supplementation. Am. J. Ophthalmol. 128: $155-164$

7. Lewis G, Mervin K, Valter K, Maslim J, Kappel PJ, Stone J and Fisher S (1999) Limiting the proliferation and reactivity of retinal Muller cells during experimental retinal detachment: the value of oxygen supplementation. Am. J. Ophthalmol. 128: 165-172

8. Mikhailov V, Mikhailova M, Degenhardt K, Venkatachalam MA, White E and Saikumar $P$ (2003) Association of Bax and Bak homo-oligomers in mitochondria. Bax requirement for Bak reorganization and cytochrome $c$ release. J. Biol. Chem. 278: 5367-5376

9. Mosinger Ogilvie J, Deckwerth TL, Knudson CM and Korsmeyer SJ (1998) Suppression of developmental retinal cell death but not of photoreceptor degeneration in Bax-deficient mice. Invest. Ophthalmol. Vis. Sci. 39: 1713-1720
10. Frasson M, Sahel JA, Fabre M, Simonutti M, Dreyfus H and Picaud S (1999) Retinitis pigmentosa: rod photoreceptor rescue by a calcium-channel blocker in the rd mouse. Nat. Med. 5: 1183-1187

11. Noell WK, Walker VS, Kang BS and Berman S (1966) Retinal damage by light in rats. Invest. Ophthalmol. 5: 450-473

12. Hafezi F, Steinbach JP, Marti A, Munz K, Wang ZQ, Wagner EF, Aguzzi A and Reme CE (1997) The absence of $c$-fos prevents light-induced apoptotic cell death of photoreceptors in retinal degeneration in vivo. Nat. Med. 3: 346-349

13. Wenzel A, Grimm C, Marti A, Kueng-Hitz N, Hafezi F, Niemeyer G and Reme CE (2000) C-fos controls the 'private pathway' of light-induced apoptosis of retinal photoreceptors. J. Neurosci. 20: 81-88

14. Poon HK, Tso MO and Lam TT (2000) c-Fos protein in photoreceptor cell death after photic injury in rats. Invest. Ophthalmol. Vis. Sci. 41: 2755-2758

15. Portera-Cailliau C, Sung CH, Nathans J and Adler R (1994) Apoptotic photoreceptor cell death in mouse models of retinitis pigmentosa. Proc. Natl. Acad. Sci. USA 91: 974-978

16. Li ZY, Tso MO, Wang HM and Organisciak DT (1985) Amelioration of photic injury in rat retina by ascorbic acid: a histopathologic study. Invest. Ophthalmol. Vis. Sci. 26: 1589-1598

17. Noell WK, Organisciak DT, Ando H, Braniecki MA and Durlin C (1987) Ascorbate and dietary protective mechanisms in retinal light damage of rats: electrophysiological, histological and DNA measurements. Prog. Clin. Biol. Res. 247: 469-483

18. Tanito M, Masutani H, Nakamura H, Ohira A and Yodoi J (2002) Cytoprotective effect of thioredoxin against retinal photic injury in mice. Invest. Ophthalmol. Vis. Sci. 43: 1162-1167

19. Chen L, Dentchev T, Wong R, Hahn P, Wen R, Bennett J and Dunaief JL (2003) Increased expression of ceruloplasmin in the retina following photic injury. Mol. Vis. 9: 151-158

20. Farlie PG, Dringen R, Rees SM, Kannourakis G and Bernard O (1995) bcl-2 transgene expression can protect neurons against developmental and induced cell death. Proc. Natl. Acad. Sci. USA 92: 4397-4401

21. Bonfanti L, Strettoi E, Chierzi S, Cenni MC, Liu XH, Martinou JC, Maffei L and Rabacchi SA (1996) Protection of retinal ganglion cells from natural and axotomy-induced cell death in neonatal transgenic mice overexpressing bcl-2. J. Neurosci. 16: 4186-4194

22. He L, Perkins GA, Poblenz AT, Harris JB, Hung M, Ellisman MH and Fox DA (2003) Bcl-xL overexpression blocks bax-mediated mitochondrial contact site formation and apoptosis in rod photoreceptors of lead-exposed mice. Proc. Natl. Acad. Sci. USA 100: 1022-1027

23. Chen J, Flannery JG, LaVail MM, Steinberg RH, Xu J and Simon MI (1996) bcl2 overexpression reduces apoptotic photoreceptor cell death in three different retinal degenerations. Proc. Natl. Acad. Sci. USA 93: 7042-7047

24. Joseph RM and Li T (1996) Overexpression of Bcl-2 or Bcl-XL transgenes and photoreceptor degeneration. Invest. Ophthalmol. Vis. Sci. 37: 2434-2446

25. Eversole-Cire P, Concepcion FA, Simon MI, Takayama S, Reed JC and Chen J (2000) Synergistic effect of Bcl-2 and BAG-1 on the prevention of photoreceptor cell death. Invest. Ophthalmol. Vis. Sci. 41: 1953-1961

26. Oltvai ZN, Milliman CL and Korsmeyer SJ (1993) Bcl-2 heterodimerizes in vivo with a conserved homolog, Bax, that accelerates programmed cell death. Cell 74: 609-619

27. Gordon WC, Casey DM, Lukiw WJ and Bazan NG (2002) DNA damage and repair in light-induced photoreceptor degeneration. Invest. Ophthalmol. Vis. Sci. 43: 3511-3521

28. Grimm C, Wenzel A, Hafezi F, Yu S, Redmond TM and Reme CE (2000) Protection of Rpe65-deficient mice identifies rhodopsin as a mediator of lightinduced retinal degeneration. Nat. Genet. 25: 63-66

29. Pequignot MO, Provost AC, Salle S, Taupin P, Sainton KM, Marchant D, Martinou JC, Ameisen JC, Jais JP and Abitbol M (2003) Major role of BAX in apoptosis during retinal development and in establishment of a functional postnatal retina. Dev. Dyn. 228: 231-238

30. Maroto R and Perez-Polo JR (1997) BCL-2-related protein expression in apoptosis: oxidative stress versus serum deprivation in $\mathrm{PC} 12$ cells. J. Neurochem. 69: 514-523

31. Liang KY and Zeger SL (1986) Longitudinal data analysis using generalized linear models. Biometrika 73: 13-22

32. Lyubarsky AL and Pugh Jr EN (1996) Recovery phase of the murine rod photoresponse reconstructed from electroretinographic recordings. J. Neurosci. 16: 563-571 